\title{
IN-HOME TELEREHABILITATION FOR PROXIMAL HUMERUS FRACTURES: A PILOT STUDY
}

\author{
MICHEL TOUSIGNANT, PT, PHD ${ }^{1,2}$, ANNE-MARIE GIGUĖE, MPT11, MARILÈNE MORIN, \\ MPT1, JULIE PELLETIER, MPT1, ANNIE SHEEHY, MPT¹, FRANÇOIS CABANA, MD³
}

${ }^{1}$ SCHOOL OF REHABILITATION, FACULTY OF MEDICINE AND HEALTH SCIENCES, UNIVERSITÉ DE SHERBROOKE, SHERBROOKE, QUÉBEC, CANADA

${ }^{2}$ RESEARCH CENTRE ON AGING, UNIVERSITY INSTITUTE OF GERIATRICS OF SHERBROOKE, SHERBROOKE, QUÉBEC, CANADA

${ }^{3}$ ORTHOPAEDIC SURGERY DIVISION, DEPARTMENT OF DURGERY, FACULTY OF MEDICINE AND HEALTH SCIENCES, UNIVERSITÉ DE SHERBROOKE, SHERBROOKE, QUÉBEC, CANADA

\section{ABSTRACT}

The objective of this study was to investigate the feasibility of an in-home telerehabilitation program for proximal humerus fractures. Seventeen patients with proximal humerus fractures were recruited by an orthopedic specialist during emergency room visits. Telerehabilitation treatments were given at the patient's home over an 8-week period using a videoconferencing system. Pain (Short-Form McGill Pain Questionnaire [SF-MPQ]), disabilities including shoulder range of motion (flexion, extension, internal rotation, external rotation, abduction), and upper limb function (Disability of the Arm, Shoulder and Hand questionnaire [DASH]) were measured in face-to-face evaluations before (T1) and immediately after (T2) the program. Participant satisfaction with the health care received was also evaluated at T2 with the Health care satisfaction questionnaire. All the clinical outcomes improved post-intervention $(p<0.05)$. Also, patient satisfaction was high (overall score of $82 \pm 7 \%$ ). Therefore, inhome teletreatment seems to be a promising way to dispense rehabilitation services for this population.

Keywords: Proximal humerus fracture, range of motion, satisfaction, telerehabilitation

Osteoporosis is a serious concern, especially in association with falls in older adults. Falls are a cause of increasing morbidity. In fact, one out of three older adults falls at least once a year, and $10 \%$ of these falls result in a fracture (Hébert \& Arcand, 2007). Fractures involving the proximal humerus are very common (Lübbeke et al., 2005; Saari, Heikkinen, Sakari-Rantala \& Rantanen, 2007).

Humeral fractures can be treated surgically (e.g. with plates and screws) or conventionally with a splint or cast (Handoll, Ollivere, \& Rollins, 2010). Conservative treatment tends to be recommended for older adults to avoid complications from surgery. However, regardless of the type of treatment, rehabilitation follow-up is required to prevent loss of function resulting from the fracture. In fact, physiotherapy has been shown to be effective in improving functional status, decreasing pain and increasing shoulder range of motion (ROM) (Hodgson, Mawson, \& Stanley,
2003; Lefevre-Colau, 2007). Currently, rehabilitation services are provided in hospital or through home care. However, only $37.2 \%$ of people with upper limb fractures receive physiotherapy in hospital (Lübbeke et al., 2005). Fracture rehabilitation services are therefore greatly underutilized. Possible explanations for the lack of rehabilitation users are that services are not readily available in remote areas and older people cannot always move to receive care (Burdea, Popescu, Hentz, \& Colbert, 2000). Thus, new strategies for delivering health care should be developed to enhance access to rehabilitation for humeral fractures. As the majority of patients with this type of fracture are elderly, it is important to adapt existing services to their condition.

Telehealth, which is an alternative to a conventional service delivery method, is defined as an application which uses telecommunications technologies to provide services 
(Bashshur, Shannon, Krupinski, \& Grigsby, 2011; Romanow, 2002). Four domains are used in clinical practice: (1) tele-education, (2) teleconsultation, (3) telemonitoring, and (4) teletreament. More specifically, teletreatment is a new approach in the rehabilitation domain which allows the patient to receive physiotherapy at home, without a professional visit. This innovative way could help to increase access to rehabilitation services in remote areas and facilitate treatment for older adults who cannot move to receive care.

To date, telerehabilitation has been tested with diverse populations, including individuals with orthopedic (Eriksson, Lindström, \& Ekenberg, 2011; Tousignant, Boissy, Corriveau, Moffet, 2006; Tousignant et al., 2011a; Russell, Buttrum, Wootton, \& Jull, 2004) and neurological conditions (Durfee, Carey, Nuckley, \& Deng, 2009; Giansanti, Morelli, Maccioni, \& Costantini, 2009a; Giansanti, Tiberi, Silvestri, \& Maccioni, 2009b; Hermann et al., 2010; Huijgen et al., 2008; Lange, Flynn, \& Rizzo, 2009; Piron, Tonin, Trivello, Battistin, \& Dam, 2004; Piron et al., 2009), as well as healthy (Wu, \& Keyes, 2006; Wu, Keyes, Callas, Ren, \& Bookchin, 2010) and frail elderly (Hoenig, Nusbaum, \& Brummel-Smith, 1997). In general, results of these studies are very promising, and support the feasibility and effectiveness of this new health care service. To our knowledge, no study on telerehabilitation has been done with a population with humerus fractures. Therefore, the main purpose of this study was to evaluate the feasibility of an in-home teletreatment program for individuals with proximal humerus fractures. The secondary objectives of this study were to: (1) compare upper limb and shoulder impairments (disability, range of motion and pain) before and after the intervention, and (2) evaluate participants' satisfaction with the care received.

\section{METHODS}

\section{DESIGN}

This pilot study had a pre-experimental design with pre/post-tests without a control group. Participants were assessed before the telerehabilitation program (T1), and after the 8-week program (T2).

\section{SAMPLE}

Patients with a proximal humerus fracture were recruited by direct referral from an orthopedic specialist in the orthopedic department at a university hospital (Centre Hospitalier Universitaire de Sherbrooke [CHUS]) during their visits to emergency. Inclusion criteria were to: (1) have conservative medical treatment (no surgery), (2) be able to do exercises, (3) have sufficient verbal and written understanding of instructions to participate in remote treatment and fill out questionnaires, and (4) have access to high speed Internet. The only exclusion criterion was to have an intra-articular proximal humerus fracture. At the hospital, an orthopedic specialist or research nurse provided information to potential participants about the purpose of the study. If verbal consent was obtained, the research team contacted patients to give more information about the study and verify their interest in participating. If they agreed to the study terms and conditions, they were asked to sign the consent form and take part in the first assessment (T1).

\section{TECHNOLOGICAL INFRASTRUCTURE FOR TELEREHABILITATION SERVICES}

Based on a modular design, a generic platform was built (Tousignant et al., 2011a), integrating commercial systems and peripherals with custom software, TeRA. In each of those systems, a videoconferencing unit was used to provide a wide-angle pan-tilt-zoom camera, an omnidirectional microphone and an embedded codec for audio-video compression (h.264 and G711).

\section{INDEPENDENT VARIABLE: PHYSIOTHERAPY TELEREHABILITATION PROGRAM}

The intervention consisted of a telerehabilitation program over 8 consecutive weeks. The treatment program was delivered twice a day, every day, either supervised by a physiotherapist through telerehabilitation or unsupervised. Patients had 2 telerehabilitation sessions in weeks 1, 3 and 5 , and only 1 in weeks 2, 4, 6, 7, and 8 . Each session lasted for about 30 to 45 minutes and was divided into 3 parts: (1) warm-up, (2) treatment program, and (3) question period. The treatment program was adjusted for each participant according to the number of weeks post-fracture. However, every exercise program involved 4 exercise types based on the orthopedic physician's specifications: (1) stretching, (2) pain control, (3) active/active-assisted ROM, and (4) muscle building. The physiotherapist also adjusted the progression of the exercises according to the patient's progress. Program adherence between teletreatments was evaluated by logs. Participants had to record in their log each time they did the treatment program.

\section{DEPENDENT VARIABLES AND DATA COLLECTION}

Three outcome measures were evaluated before (T1) and after (T2) the program (pain, shoulder ROM and upper limb function) and satisfaction with health services received was evaluated at T2. All assessments were done at the research centre by a research assistant and were standardized. 
Pain was assessed with the Short-Form McGill Pain Questionnaire (SF-MPQ) (Melzack, 1987; Strand, Ljunggren, Bogen, Ask, \& Johnsen, 2008; Wright, Mundson, McCreary, 2001). This multidimensional test evaluates the sensory and affective dimensions of pain using 15 pain descriptors, ranked on a 4-point intensity scale $(0=$ none, 1 $=$ mild, 2 = moderate, 3 = severe). It has high test-retest reliability (Strand et al., 2008) and good content validity (Wright, 2001). An additional question was added to the questionnaire concerning the intensity of pain during the previous week using a visual analogue scale (VAS) (/100).

Shoulder ROM was measured with a conventional goniometer. This instrument is known to be reliable and valid. The following passive measurements were taken: (1) flexion, (2) extension, (3) internal rotation, (4) external rotation, and (5) abduction. These choices were based on movements that most influence shoulder function.

To assess upper limb function, the 30 -item French version of the Disability of the Arm, Shoulder and Hand questionnaire (F-DASH) (Fayad et al., 2008) was used. This questionnaire assesses participants' degree of difficulty in performing various physical activities because of an arm, shoulder or hand problem (21 items), the severity of the pain symptoms (5 items), and the effect of the problem on social activities, work and sleep as well as its psychological impact (4 items). Difficulty/symptoms are rated on a 5-level ordinal scale ranging from "no difficulty or symptoms" to "unable to perform activity or very severe symptoms". The score is out of a total of 100 and the higher the score, the greater the degree of incapacity. This questionnaire presented an interclass correlation coefficient of 0.95 , which demonstrates excellent test-retest reliability, and a Cronbach alpha of 0.96, which indicates good internal consistency (Fayad et al., 2008). The two optional scales of the DASH (work and sport/music) were not used in this study.

Finally, user satisfaction with health services received was assessed with the French version of the Health Care Satisfaction Questionnaire (Gagnon, Hébert, Dubé, \& Dubois, 2006). The questionnaire has 26 items divided into three domains: (1) relationship with the professional, (2) organization of services, and (3) delivery of services. The total score is adjusted in percentage (/100).

\section{STATISTICAL ANALYSES}

The sociodemographic characteristics of the population are presented with the usual descriptive statistics (mean, standard deviation, percentage). The difference between the clinical outcomes measured before (T1) and after (T2) the program was analyzed using nonparametric Wilcoxon signed rank test, with the significance level set at 0.05 . All of these analyses were performed with SPSS version 18.0.

\section{RESULTS}

Twenty one patients with non-operatively treated proximal humerus fractures were enrolled in this pilot study. Among them, two refused to participate before the beginning of the intervention, one was excluded before the beginning of the intervention and one withdrew from the project in the middle of the intervention period and did not complete the second evaluation. In total, the analyses included the remaining 17 participants. The participants' characteristics are presented in Table 1.

Table 1. Participants' Characteristics $(n=17)$

\begin{tabular}{|c|c|c|c|c|}
\hline \multicolumn{2}{|l|}{ Variables } & Means \pm SD & $\mathbf{n}$ & $\%$ \\
\hline \multicolumn{2}{|l|}{ Age (yrs) } & $65 \pm 11$ & - & - \\
\hline \multicolumn{2}{|l|}{ Height (cm) } & $162 \pm 8$ & - & - \\
\hline \multicolumn{2}{|l|}{ Weight (kilos) } & $66 \pm 11$ & & - \\
\hline \multicolumn{2}{|c|}{ Years of scolarity (yrs) } & $13 \pm 4$ & & - \\
\hline \multirow[t]{2}{*}{ Sex } & Men & - & 2 & 12 \\
\hline & Women & - & 15 & 88 \\
\hline \multirow[t]{2}{*}{ Dominance } & Left- handed & & 3 & 18 \\
\hline & Right-handed & - & 14 & 82 \\
\hline \multirow[t]{3}{*}{ Occupation } & Retired & - & 13 & 76 \\
\hline & Worker & - & 2 & 12 \\
\hline & Semi-retired & - & 2 & 12 \\
\hline \multirow[t]{2}{*}{ Living alone? } & Yes & - & 7 & 41 \\
\hline & No & - & 10 & 59 \\
\hline
\end{tabular}

\section{CLINICAL OUTCOMES}

PAIN

The pain decreased significantly between $\mathrm{T} 1$ and $\mathrm{T} 2$ as indicated by the SF-MPQ score (difference of $10.6 \pm 12.4$; $p$ $=0.003$ ) and the VAS (difference of $26.3 \pm 21.8 ; p=0.001$ ). The demonstrated pain reduction was greater than the minimal clinically important difference (difference over 5/45 for total descriptors) (Strand et al., 2008).

\section{SHOULDER ROM}

The shoulder ROM results showed an improvement for all the movements evaluated. The pre/post-program difference was greater than the interrater minimal clinical difference (more than 5-10 degrees) (Edward \& McFarland, 2006) for all movements (see Figure 1). 


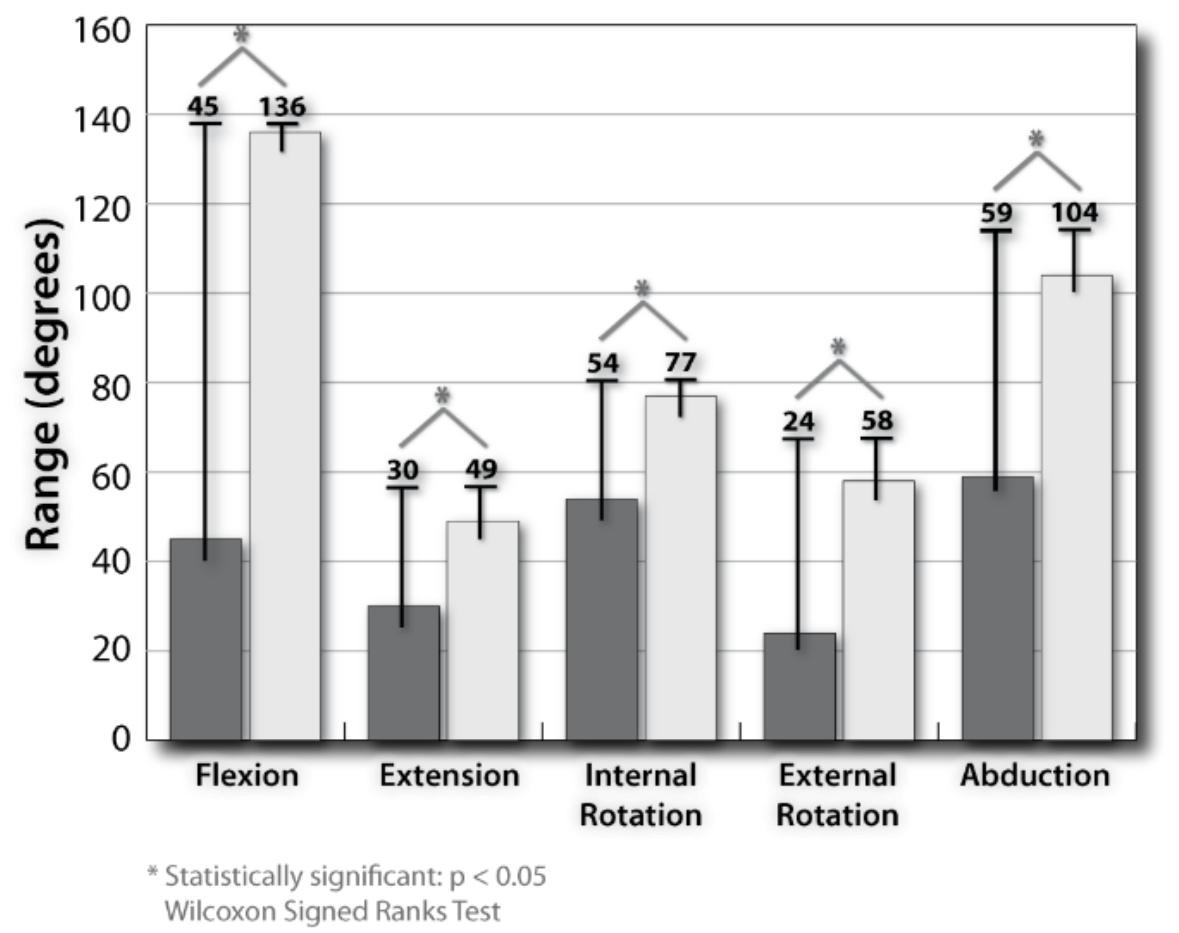

Figure 1. Shoulder range of motion

\section{UPPER LIMB FUNCTION}

On the F-DASH questionnaire, a difference of $42.1 \pm$ $11.4(p<0.001)$ in upper limb function was observed. This is much greater than the minimal clinical difference (change over 15/100) (Beaton, Davis, Hudak, \& McConnell, 2001).
USER SATISFACTION WITH HEALTH SERVICES RECEIVED

The participants' overall satisfaction was very good (82 $\pm 7 \%$ ). For all the other factors, the score was over $79 \%$. Results on the Health Care Satisfaction Questionnaire are presented in Table 2.

Table 2. Patients' Satisfaction Toward Received Care

\begin{tabular}{lr}
\hline & Mean \pm SD \\
\hline Global score (\%) & $82 \pm 7$ \\
Factor 1 score: Satisfaction with regards to the relationship with the health care professional (\%) & $88 \pm 10$ \\
Factor 2 score: Satisfaction with the services delivered (\%) & $79 \pm 10$ \\
Factor 3 score: Satisfaction with the general health care organization (\%) & $89 \pm 13$ \\
\hline
\end{tabular}

\section{DISCUSSION}

The objective of this pilot study was to investigate the feasibility of delivering a telerehabilitation program for patients with non-surgically treated proximal humerus fractures. The results show that telerehabilitation seems to be a good service delivery method for this population. To our knowledge, this is the first study to demonstrate the feasibility of carrying out a complete telerehabilitation program for this population.

This study showed statistically and clinically significant positive results for all the outcomes measured after the program. For the first outcome, pain, the sensory and affective aspects of pain scored statistically lower after the intervention, as did pain intensity measured on a VAS. As reducing pain is very important for improving participants' 
quality of life (Hawkins et al., 2013), the results obtained in this pilot study are very promising.

For the second outcome, shoulder ROM, the results were statistically significant for all movements (flexion, extension, internal rotation, external rotation, abduction). As expected, the gain in ROM (degrees) was almost doubled in the five measures taken. This significant improvement in $\mathrm{ROM}$ is associated with good recovery following a proximal humerus fracture.

The results obtained on the F-DASH questionnaire concerning shoulder function are as outstanding as the ones obtained on the ROM measures. The questionnaire scores demonstrated that upper limb function was more than twice as good after the program than prior to it. The large difference obtained indicated that the participants were more likely to perform their daily activities after the intervention.

Concerning users' satisfaction with the health care received, the scores obtained in every domain of satisfaction demonstrated a level of satisfaction over $79 \%$. This is slightly lower than in a previous study published by our team concerning patient satisfaction with technology for post-knee arthroplasty (Tousignant et al., 2011b). In that study, the general satisfaction of telerehabilitation users was $90 \%$ and satisfaction with the three different factors was over $85 \%$. As patient satisfaction is very important and highly correlated with patient compliance and motivation (Piron et al., 2008), the good scores obtained on the satisfaction questionnaire are a good indicator of the participants' motivation to use this health service following a proximal humerus fracture.

\section{STRENGTHS AND LIMITATIONS}

Our study has a potential selection bias because patients who agreed to participate were probably more motivated and willing to explore new types of therapy. One of the strengths was that we avoided information bias by ensuring standardization of our assessors and choosing valid measuring instruments. However, the lack of a control group is a serious limitation of our study. Natural recovery from this acute condition must be taken into consideration when interpreting the results. The participants' confidence in their physical progress is a positive aspect of this acute condition.

\section{CONCLUSION}

Teletreatment seems to be a promising way to dispense rehabilitation services for patients with proximal humerus fractures. Further studies are needed with a more powerful design (e.g., addition of a control group, clinical trial) to measure the efficacy of delivering a rehabilitation program for proximal humerus fractures through teletreatment. However, even with the small sample size of this pilot study, the feasibility of in-home rehabilitation for proximal humerus fractures was demonstrated.

\section{ACKNOWLEDGEMENT}

We would like to thank all the participants that took part in this research project.

\section{REFERENCES}

Bashshur, R., Shannon, G., Krupinski, E., \& Grigsby, J. (2011). The taxonomy of telemedicine. Telemedicine and e-Health, 17, 484-494. doi: 10.1089/tmj.2011.0103.

Beaton, D., Davis, A., Hudak, P., \& McConnell, S. (2001). The DASH (disabilities of the arm, shoulder and hand) outcome measure: What do we know about it now? Hand Therapy, 6, 109-118.

Burdea, G., Popescu, V., Hentz, V., \& Colbert, K. (2000). Virtual reality-based orthopedic telerehabilitation. IEEE Transactions on Rehabilitation Engineering, 8, 430-432.

Durfee, W., Carey, J., Nuckley, D., \& Deng, J. (2009). Design and implementation of a home stroke telerehabilitation system. Conference Proceedings: ... Annual International Conference of the IEEE Engineering in Medecine and Biology Society. Annual Conference, 2009, 2422-2425. doi: 10.1109/IEMBS.2009.5334951.

Edward, G., \& McFarland, M.D. (2006) Examination of the shoulder: The complete guide. Thieme.

Eriksson, L., Lindström, B., \& Ekenberg, L. (2011). Patients' experiences of telerehabilitation at home after shoulder joint replacement. Journal of Telemedicine and Telecare, 17, 25-30. doi: 10.1258/jtt.2010.100317.

Fayad, F., Lefevre-Colau, M.M., Macé, Y., Fermanian, J., Mayoux-Benhamou, A., Roren, A., ... Poiraudeau, S. (2008). Validation of the french version of the disability of the arm, shoulder and hand questionnaire (F-DASH). Joint, Bone, Spine: Revue du Rhumatisme, 75, 195200.

Gagnon, M., Hébert, R., Dubé, M., \& Dubois, M.F. (2006). Development and validation of the health care satisfaction questionnaire (HCSQ) in elders. Journal of Nursing Measurement, 14, 190-204.

Giansanti, D., Morelli, S., Maccioni, G., \&Costantini, G. (2009a). Toward the design of a wearable system for fall-risk detection in telerehabilitation. Telemedicine and e-Health, 15, 296-299. doi: 10.1089/tmj.2008.0106. 
Giansanti, D., Tiberi, Y., Silvestri, G., \& Maccioni, G. (2009b). Toward the integration of novel wearable stepcounters in gait telerehabilitation after stroke. Telemedicine and e-Health, 15, 105-111. doi: 10.1089/tmj.2008.0051.

Handoll, H.H., Ollivere, B.J., \& Rollins, K.E. (2010). Interventions for treating proximal humeral fractures in adults. The Cochrane Database of Systematic Reviews, 12, CD000434. doi: 10.1002/14651858.CD000434.pub3.

Hawkins, K., Musich, S., Bottone, F.G. Jr., Ozminkowski, R.J., Cheng, Y., Rush, S., ... Yeh, C.S. (2013). The impact of pain on physical and mental quality of life in adults 65 and older. Journal of Gerontological Nursing, 39, 32-44. doi: 10.3928/00989134-20130402-02.

Hébert, R. \& Arcand, M. (2007). Précis pratique de gériatrie (3e edition). Edisem Maloine.

Hermann, V.H., Herzog, M., Jordan, R., Hofherr, M., Levine, P., \& Page, S.J. (2010). Telerehabilitation and electrical stimulation: An occupation-base, client-centered stroke intervention. American Journal of Occupational Therapy, 64, 73-81.

Hodgson, S.A., Mawson, S.J., \& Stanley, D. (2003). Rehabilitation after two-part fractures of the neck of the humerus. Journal of Bone and Joint Surgery. British, 85, 419-422.

Hoenig, H., Nusbaum, N., \& Brummel-Smith, K. (1997). Geriatric rehabilitation: State of the art. Journal of the American Geriatrics Society, 45, 1371-1381.

Huijgen, B.C., Vollenbroek-Hutten, M.M., Zampolini, M., Opisso, E., Bernabeu, M., Van Nieuwenhoven, J., ... Hermens, H.J. (2008). Feasibility of a home-based telerehabilitation system compared to usual care: Arm/hand function in patients with stroke, traumatic brain injury and multiple sclerosis. Journal of Telemedicine and Telecare, 14, 249-256. doi: 10.1258/jtt.2008.080104.

Lange, B., Flynn, S.M., \& Rizzo, A.A. (2009). Game-based telerehabilitation. European Journal of Physical and Rehabilitation Medicine, 45, 143-151.

Lefevre-Colau, M.M., Babinet, A., Fayad, F., Fermanian, J., Anract, P., Roren, A., et al. (2007). Immediate mobilization compared with conventional immobilization for the impacted nonoperatively treated proximal humeral fracture: A randomized controlled trial. Journal of Bone and Joint Surgery, 89, 2582-2590.

Lübbeke, A., Stern, R., Grab, B., Herrmann, F., Michel, J.P. \& Hoffmeyer, P. (2005). Upper extremity fractures in the elderly: Consequences on utilization of rehabilitation care. Aging Clinical and Experimental Research, 17, 276-280.
Melzack, R. (1987). The short-form mcgill pain questionnaire. Pain, 30, 191-197.

Piron, L., Tonin, P., Trivello, E., Battistin, L., \& Dam, M. (2004). Motor tele-rehabilitation in post-stroke patients. Medical Informatics and the Internet in Medicine, 29, 119-125.

Piron, L., Turolla, A., Tonin, P., Piccione, F., Lain, L., \& Damm, M. (2008). Satisfaction with care in post-stroke patients undergoing a telerehabilitation programme at home. Journal of Telemedicine and Telecare, 14, 257 260. doi: 10.1258/jtt.2008.080304.

Piron, L., Turolla, A., Agostini, M., Zucconi, C., Cortese, F., Zampolini, M., ... Tonin, P. (2009) Exercises for paretic upper limb after stroke: A combined virtual-reality and telemedicine approach. Journal of Rehabilitation Medicine, 41, 1016-1102. doi: 10.2340/16501977-0459.

Romanow, R. (2002). Guidé par nos valeurs : L'avenir des soins de santé au Canada. Ottawa, Santé Canada. Retrieved from: http://publications.gc.ca/site/archiveearchived.html?url=http://publications.gc.ca/collections/C ollection/CP32-85-2002F.pdf

Russell, T.G., Buttrum, P., Wootton, R., \& Jull, G.A. (2004). Rehabilitation after total knee replacement via lowbandwidth telemedicine: The patient and therapist experience. Journal of Telemedicine and Telecare, 10, 85-87.

Saari, P., Heikkinen, E., Sakari-Rantala, R. \& Rantanen, T. (2007). Fall-related injuries among initially 75- and 80year old people during a 10-year follow-up. Archives of Gerontology and Geriatrics, 45, 207-215.

Strand, L.I., Ljunggren, A.E., Bogen, B., Ask, T., \& Johnsen, T.B. (2008). The short-form mcgill pain questionnaire as an outcome measure: Test-retest reliability and responsiveness to change. European Journal of Pain, 12, 917-925. doi: 10.1016/j.ejpain.2007.12.013

Tousignant, M., Boissy, P., Corriveau, H., Moffet, H. (2006) In home telerehabilitation for older adults after discharge from an acute hospital or rehabilitation unit: A proof-of-concept study and costs estimation. Disability and Rehabilitation: Assistive Technology, 1, 209-216.

Tousignant, M., Moffet, H., Boissy, P., Corriveau, H., Cabana, F., Marquis, F. (2011a) A randomized controlled trial of home telerehabilitation for post-knee arthroplasty. Journal of Telemedicine and Telecare 17, 195-198.

Tousignant, M., Boissy, P., Moffet, H., Corriveau, H., Cabana, F., Marquis, F., ... Simard, J. (2011b). Patients' satisfaction of healthcare services and perception with in-home telerehabilitation and physiotherapists' satisfaction toward technology for postknee arthroplasty: An embedded study in a randomized trial. Telemedicine Journal and e-Health, 17, 376-382. 
International Journal of Telerehabilitation • telerehab.pittedu

Wright, K.D., Mundson, G.J., \& McCreary, D.R. (2001) Factorial validity of the short-form mcgill pain questionnaire (SF-MPQ). European Journal of Pain, 5, 279-285.

Wu, G., \& Keyes, L.M. (2006). Group tele-exercise for improving balance in elders. Telemedicine and eHealth, 12, 561-570.
Wu, G., Keyes, L., Callas, P., Ren, X., \& Bookchin, B. (2010). Comparison of telecommunication, community, and home-based tai chi exercise programs on compliance and effectiveness in elders at risk for falls. Archives of Physical Medicine and Rehabilitation, 91, 849-856. doi: 10.1016/j.apmr.2010.01.024. 
